\title{
Rheological Properties and Phase Inversion of Polypropylene and Poly(styrene-co-acrylonitrile) Blends
}

\author{
Min Soo Han, Won Jin SeO, Han Sung PaIK, Jae Chun Hyun, ${ }^{*}$ \\ Jae Wook LEE, and Woo Nyon KIM ${ }^{\dagger}$ \\ Department of Chemical and Biological Engineering, Applied Rheology Center, \\ Korea University, Anam-dong, Seoul 136-701, Korea \\ *Department of Chemical Engineering, Sogang University, Shin Su-dong, Seoul 121-742, Korea
}

(Received May 13, 2002; Accepted September 12, 2002)

\begin{abstract}
Extension and shear viscosities of polypropylene (PP) and poly(styrene-co-acrylonitrile) (SAN) were investigated by the advanced rheometric expansion system (ARES), capillary rheometer, and extension rheometer. Blends of PP and SAN were prepared by screw extrusion with weight fraction of PP in the blends from 0.9 to 0.10 . Shear and transient extension viscosity ratios were used in the Utracki, Miles and Zurek, and Metelkin and Blekht models to obtain the weight fraction of phase inversion for the blends. For the Utracki model, the weight fraction of the phase inversion for $\mathrm{PP}$ in the PP/SAN blend was 0.32 and 0.46 for the shear viscosity and transient extension viscosity ratios, respectively. From scanning electronic microscopy, the phase inversion was in the region of 45/55 PP/SAN blends. When the transient extension viscosity ratio was applied in the Utracki model, phase inversion in the PP/SAN blend showed good agreement with morphological studies of the blends.
\end{abstract}

KEY WORDS Polymer Blends / Rheological Properties / Morphology / Phase Inversion /

Polymer blending is effective to obtain materials with specific properties. Most polymers are immiscible, as that, blending usually leads to heterogeneous morphology. ${ }^{1-4}$ When two immiscible polymers are compounded in mixing, dispersed and co-continuous morphology are often observed. ${ }^{5}$ Polymer blends with co-continuous morphology have various interesting properties originating from the special arrangement of phases. ${ }^{6}$ From the industrial point of view, these materials exhibit good impact arising from the interpenetrating arrangement of phase. Such morphology is usually observed for composition around the phase inversion point. $^{7}$

Polymer blends exhibiting co-continuous structures to possess relatively stable morphologies, which seem to coarsen upon annealing without change in morphology. The influence of composition and viscosity ratio on the morphology of immiscible blends has been widely studied, ${ }^{8,9}$ while in the co-continuity region morphology have been studied little. ${ }^{10-14}$

Co-continuity is observed within a range of compositions rather than at a single point, ${ }^{15-17}$ usually at the point of phase inversion. ${ }^{12}$ Several semi-empirical models, like the Utracki, ${ }^{18}$ Miles and Zurek, ${ }^{19}$ and Metelkin and Blekht ${ }^{20}$ phase inversion models, appear in the literature to predict phase inversion. In semi-empirical models, shear or complex viscosity ratio is used to predict this point. Recently, Willemse et $a .^{21-23}$ proposed an phase inversion model to predict the range of compositions of co-continuous structures in polymer blends by considering a co-continuous structure as a dense packing of randomly oriented rodlike particles of the minor phase. The Willemse model relates the critical volume fraction of the minor phase at complete co-continuity to the matrix viscosity, interfacial tension, shear rate, and phase dimension. In the Willemse model, prediction of phase inversion composition of polymer blends is not easy because the phase dimension has to be measured. ${ }^{14}$

For polystyrene (PS)/polyethylene (PE), poly(methyl methacrylate) (PMMA)/PE, PMMA/PS, and polycarbonate (PC)/PS blends, Mekhilef and Verhoogt ${ }^{12}$ have studied phase inversion using the shear viscosity ratio in several semi-empirical phase inversion models. The morphology of an extruded blend may be affected by extension stress in a converging part of a die. Thus, the extension viscosity ratio is more important than the shear or complex viscosity ratio. ${ }^{18}$

The present work demonstrates transient extension viscosity and shear viscosity of the polypropylene (PP)/ poly(styrene-co-acrylonitrile) (SAN) blends using advanced rheometric expansion system (ARES), capillary rheometer, and extension rheometer to predict the composition of phase inversion of the blends. Results for phase inversion were compared with those from morphological studies on PP/SAN blends. 
Table I. Characteristics of polymer samples used in PP/SAN blends

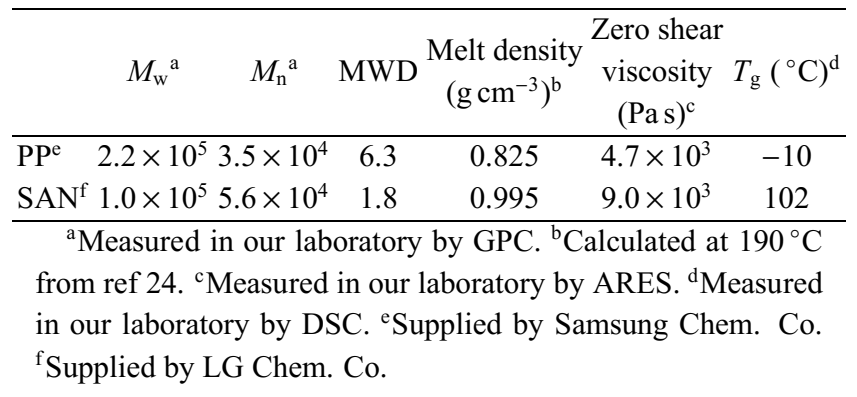

\section{EXPERIMENTAL}

\section{Polymers}

Polymers were obtained from commercial sources. PP, coded as HJ 700, was provided by Samsung Chemical Co. The SAN, coded as 81HF, was from LG Chemical Co. Characteristics and sources of PP and SAN are shown in Table I. The densities of PP and SAN at $190{ }^{\circ} \mathrm{C}$ were 0.825 and 0.995 , respectively. ${ }^{24}$

\section{Blend Preparations}

Blends with weight fractions of PP from 0.1 to 0.9 were prepared using a $20 \mathrm{~mm}$ diameter laboratory scale screw extruder, with a $24: 1$ length to diameter screw. The polymer samples were dried under vacuum $(<1 \mathrm{mmHg})$ at $100^{\circ} \mathrm{C}$ for $24 \mathrm{~h}$ and extruded at an apparent shear rate $\left(4 \mathrm{Q} / \pi \mathrm{R}^{3}\right)$ of $180 \mathrm{~s}^{-1}$. To determine the extension rate from entrance flow under extruded condition, the extrusion die had a conical entrance with an angle of $30^{\circ}$ and radius of $1 \mathrm{~mm}$. The temperatures of the extruder were set at $160{ }^{\circ} \mathrm{C}$ and $200{ }^{\circ} \mathrm{C}$ in the feeding and barrel zones, respectively. Samples were compression molded using a hot press at $190^{\circ} \mathrm{C}$ and 40 psi for $5 \mathrm{~min}$.

\section{Scanning Electron Microscopy}

The morphology of the cross-section of the extrudate prepared by cryogenic fracturing was examined by JEOL scanning electron microscopy (Model JSM $5200)$ at $20 \mathrm{kV}$ accelerating voltage after gold sputter coating (500 $\AA$ ).

\section{Rheology}

Dynamic Measurement. Dynamic measurements were carried out on ARES under oscillatory shear mode at $5 \%$ strain in a $25 \mathrm{~mm}$ parallel-plate arrangement. The sample used was prepared in a disk $2 \mathrm{~mm}$ in thickness. Frequency sweeps from 0.01 to $100 \mathrm{rad} \mathrm{s}^{-1}$ were carried out at $190{ }^{\circ} \mathrm{C}$. For all measurements, behavior of the sample was shown linear viscoelastic. ${ }^{25}$

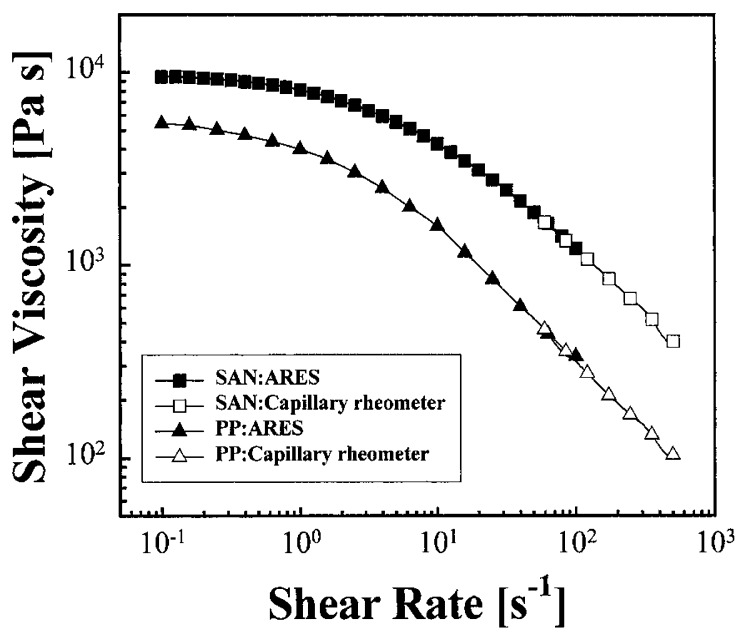

Figure 1. Viscosity of PP and SAN measured by ARES and capillary rheometer at $190{ }^{\circ} \mathrm{C}$. PP: $(\boldsymbol{\Delta})$ ARES, $(\triangle)$ capillary rheometer; SAN: (ם) ARES, $(\square)$ capillary rheometer.

Capillary Measurement. High shear rate viscosity has been determined by Gottfert capillary rheometer (Model Rheotester 1501). Three $1 \mathrm{~mm}$ diameter capillaries with length to diameter L/D ratio of 10, 20, and 30 were used. Rabinowitsch and Bagley corrections were made to obtain true shear rates of the samples.

Extension Viscosity Measurement. Measurement of uniaxial extension viscosity at constant extension rate was carried out using Meissner type extensional rheometer at $190^{\circ} \mathrm{C}$. Detail description and discussion of the reliability of the extensional rheometer are given in previous paper. ${ }^{26,27}$ Stress growth curves were recorded in uniaxial extension rates from 0.05 to $5 \mathrm{~s}^{-1}$ and accumulated strain $(\varepsilon=\dot{\varepsilon} \times t)$ up to 5 strain unit (s.u.).

\section{RESULTS AND DISCUSSION}

\section{Shear Rheology}

Figure 1 shows the shear viscosity of PP and SAN measured from ARES and capillary rheometer at $190^{\circ} \mathrm{C}$. Parallel-plate oscillatory and capillary data could be superimposed quite well in the $50-100 \mathrm{~s}^{-1}$ shear rate range for PP and SAN. At high shear rate, PP and SAN showed the power-law behavior. From Figure 1 , shear viscosities of PP and SAN were $2.08 \times 10^{2}$ and $8.36 \times 10^{2} \mathrm{Pas}$ at a shear rate of $180 \mathrm{~s}^{-1}$ which is the blending condition for PP/SAN blends, respectively.

The composition of phase inversion at which cocontinuity is observed is related to the rheology of pure materials through semi-empirical models. Utracki ${ }^{18}$ suggests a model based on the Krieger and Dougherty ${ }^{28}$ theory. The Utracki model can be used to predict the composition of phase inversion for blends with a vis- 
Table II. Weight fraction of phase inversion for PP in PP/SAN blends based on phase inversion models

\begin{tabular}{|c|c|c|}
\hline Model & $\begin{array}{c}\text { Weight fraction of PP } \\
\text { (shear viscosity ratio: } \\
\lambda=0.25 \text { ) }\end{array}$ & $\begin{array}{c}\text { Weight fraction of PP } \\
\text { (transient extension } \\
\left.\text { viscosity ratio: } \lambda_{\mathrm{e}}=0.62\right)\end{array}$ \\
\hline Utracki $^{\mathrm{a}}$ & 0.32 & 0.46 \\
\hline Miles and Zurek ${ }^{\mathrm{b}}$ & 0.17 & 0.38 \\
\hline Metelkin and Blekht ${ }^{\mathrm{c}}$ & 0.06 & 0.28 \\
\hline
\end{tabular}

cosity ratio different from unity. The Utracki phase inversion model is defined as follows:

$$
\lambda=\frac{\eta(\dot{\gamma})_{1}}{\eta(\dot{\gamma})_{2}}=\left(\frac{\phi_{\mathrm{m}}-\phi_{2}}{\phi_{\mathrm{m}}-\phi_{1}}\right)^{[\eta] \phi_{\mathrm{m}}}
$$

where $\lambda$ is the shear viscosity ratio of the blends component, $\eta(\dot{\gamma})_{i}$ viscosity of polymer $i$ at the shear rate of blending, $[\eta]$ intrinsic viscosity of the blend, $\phi_{\mathrm{m}}$ maximum packing volume fraction, and $\phi_{i}$ the volume fraction for phase inversion $\left(\phi_{1}+\phi_{2}=1\right)$. For polymer blends, the maximum packing volume fraction in eq 1 may be taken as $\phi_{\mathrm{m}}=1-\phi_{\mathrm{c}}$, where $\phi_{\mathrm{c}}$ is the critical volume fraction for percolation. ${ }^{31}$ From Utracki's work, the phase inversion of the polymer blends is well represented by eq 1 when intrinsic viscosity $[\eta]$ is $1.9 .{ }^{18}$ Theoretical $\phi_{\mathrm{c}}$ for three-dimensional spherical dispersions is 0.156 and 0 in shear and extension fields, respectively. ${ }^{18}$

From Figure 1 and eq 1, the shear viscosity ratio $(\lambda)$ of PP and SAN was 0.25 at the $180 \mathrm{~s}^{-1}$ which is the shear rate for the blending of PP and SAN. The volume fraction was converted to the weight fraction multiplied by the densities of PP and SAN at $190^{\circ} \mathrm{C}$. From eq 1, the weight fraction of phase inversion for PP in PP/SAN blends was 0.32 .

The composition of phase inversion may be obtained from the semi-empirical models of the Miles and Zurek $^{19}$ and Metelkin and Blekht. ${ }^{20}$ For blends prepared at low shear rate, Miles and Zurek proposed a theoretical prediction of phase inversion. The Miles and Zurek phase inversion model is defined as follows:

$$
\lambda=\frac{\eta(\dot{\gamma})_{1}}{\eta(\dot{\gamma})_{2}}=\frac{\phi_{1}}{\phi_{2}}
$$

When the ratio in eq 2 is lower than unity, phase 2 should form the dispersed phase in a continuous matrix of phase 1 , whereas phase 1 should disperse in phase 2 for values higher than unity.

Metelkin and Blekht also proposed a model based on the filament instability concept. The critical volume fraction for phase inversion is determined as:

$$
\begin{gathered}
\phi_{2}=\frac{1}{1+\lambda F(\lambda)} \\
F(\lambda)=1+2.25 \log \lambda+1.81(\log \lambda)^{2}
\end{gathered}
$$

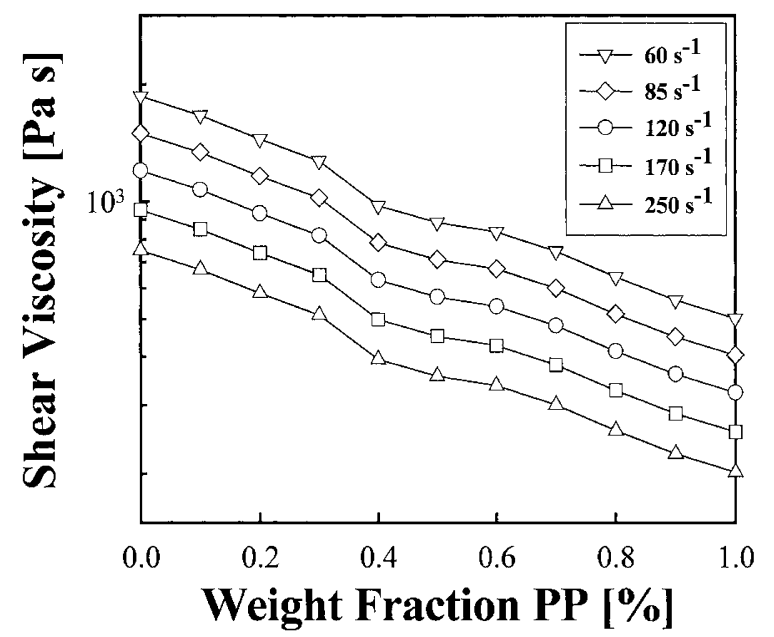

Figure 2. Shear viscosity of $\mathrm{PP} / \mathrm{SAN}$ blends at various shear rates $\left(\mathrm{s}^{-1}\right):(\nabla) 60,(\diamond) 85,(\bigcirc) 120,(\square) 170,(\triangle) 250$.

By comparison of eqs 2 and 3, the Miles and Zurek model may be regarded as a special form of the Metelkin and Blekht model, valid for $\lambda=1$.

From the shear viscosity ratio in eqs 2 and 3, the weight fractions of phase inversion for PP in PP/SAN blends were 0.17 and 0.06 , respectively, and shown in Table II.

Shear viscosity of PP/SAN blends is shown in Figure 2. Shear rates were $60,85,120,170$, and $250 \mathrm{~s}^{-1}$. From Figure 2, abrupt change in viscosity is observed at a 0.4 weight fraction for PP in the PP/SAN blend, which is close to the composition by eq 1 . This change may be related to morphological changes of PP/SAN blends. The same relation between viscosity change and morphological behavior was reported by Martinez and Williams. ${ }^{29}$

\section{Extension Rheology}

Morphology of the extruded blend may be affected by extension stress in the converging part of a die. Thus, the extension viscosity ratio may be more important than the shear viscosity ratio. ${ }^{18}$ Phase inversion would thus seem related to transient extension viscosity of components at the inversion point during mixing.

At the extruder die, the exerted strain and extension rate of PP and SAN can be determined by the Entry Flow Method. ${ }^{30,31}$ From the Entry Flow Method, strain 
accumulated in the entrance region is a function of the radius as follows:

$$
\varepsilon_{\text {entr }}=2 \ln \alpha
$$

where $\alpha$ is the barrel/capillary radii ratio. The radii ratio $(\alpha)$ of the barrel and capillary and strain $\left(\varepsilon_{\text {entr }}\right)$ were 3.25 and 2.36, respectively. Average extension rate was found by dividing strain by time for the material to flow through the entry region as follows: ${ }^{30}$

$$
<\dot{\varepsilon}>=6 \ln \alpha \frac{Q \tan \theta}{\pi R_{i}^{2} L_{i}}
$$

where $Q$ is flow rate with blending of PP and SAN blends, $\theta$ entrance angle, $R_{i}$ capillary radius, and $L_{i}$ length of the capillary. From eq 6 , the extension rate of blending was $4.10 \mathrm{~s}^{-1}$.

Assuming phase inversion to occur at the end of the extruder die, extension viscosity ratio relevant to inversion may be attained with transient extension viscosity data at $\varepsilon_{\text {entr }}$ and $<\dot{\varepsilon}>$.

Figure 3 shows transient extension viscosity $\left(\eta_{\mathrm{E}}^{+}\right)$ growth curves of PP with time, measured with an extension rheometer. Two transient extension viscosity values of PP measured at 4 and $4.10 \mathrm{~s}^{-1}$, were close so that the data at $4.10 \mathrm{~s}^{-1}$ are not shown in Figure 3. At a very low extension rate $\left(0.05 \mathrm{~s}^{-1}\right)$, steady extension viscosity $\left(\eta_{\mathrm{E}}^{\mathrm{o}}\right)$ was observed, and $\eta_{\mathrm{E}}^{\mathrm{o}}$ was close to $3 \eta_{\mathrm{o}}$ (zero shear viscosity), showing the extension rheometer to be reliable. At extension rates of $1,2,3,4$, and $5 \mathrm{~s}^{-1}$, strain hardening growth curves were observed. From Figure 3, transient extension viscosity $\left(\eta_{\mathrm{E}}\right)$ of PP at the exerted stain unit $\left(\varepsilon_{\text {entr }}=2.36\right)$ was computed.

For SAN, the same procedure can be applied, and Figure 4 shows transient extension viscosity $\left(\eta_{\mathrm{E}}^{+}\right)$ growth curves of SAN with time and strain, respectively. At a very low extension rate $\left(0.05 \mathrm{~s}^{-1}\right)$, steady extension viscosity $\left(\eta_{\mathrm{E}}^{\mathrm{o}}\right)$ was observed, and $\eta_{\mathrm{E}}^{\mathrm{o}}$ was close to $3 \eta_{\mathrm{o}}$ (zero shear viscosity). ${ }^{31}$ At extension rates of 1 , $2,3,4$, and $5 \mathrm{~s}^{-1}$, strain hardening growth curves were observed as shown in Figure 3.

From Figures 3 and 4, the transient extension viscosity at $4.10 \mathrm{~s}^{-1}$, the blending condition of PP and SAN, was $1.63 \times 10^{4}$ and $2.62 \times 10^{4} \mathrm{~Pa} \mathrm{~s}$, respectively. Transient extension viscosity ratio $\left(\lambda_{\mathrm{e}}\right)$ of the PP and SAN is thus 0.62 at the $4.10 \mathrm{~s}^{-1}$.

The composition of phase inversion for PP/SAN blends can also be obtained when the shear viscosity ratio is replaced by transient extension viscosity ratio in eq 1 . By the transient extension viscosity ratio in eq 1 , the weight fraction of phase inversion for the PP in the $\mathrm{PP} / \mathrm{SAN}$ blend was 0.46 . When the transient extension viscosity ratio is used in the eqs 2 and 3, the weight fraction of phase inversion for PP in PP/SAN blend

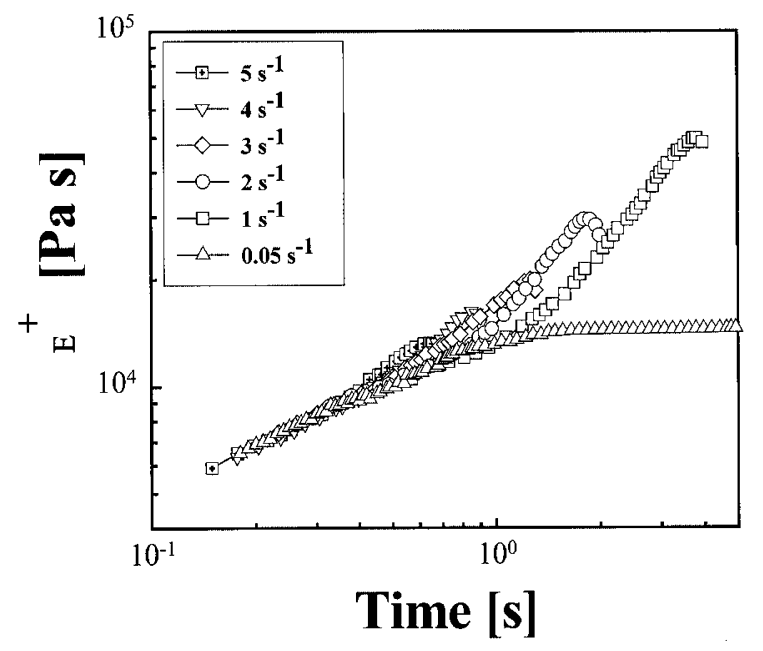

Figure 3. Transient extension viscosity growth curves at various extension rates $\left(\mathrm{s}^{-1}\right)$ with time for PP: $(\triangle) 0.05,(\square) 1,(\bigcirc) 2$, $(\diamond) 3,(\nabla) 4,(\boxplus) 5$.

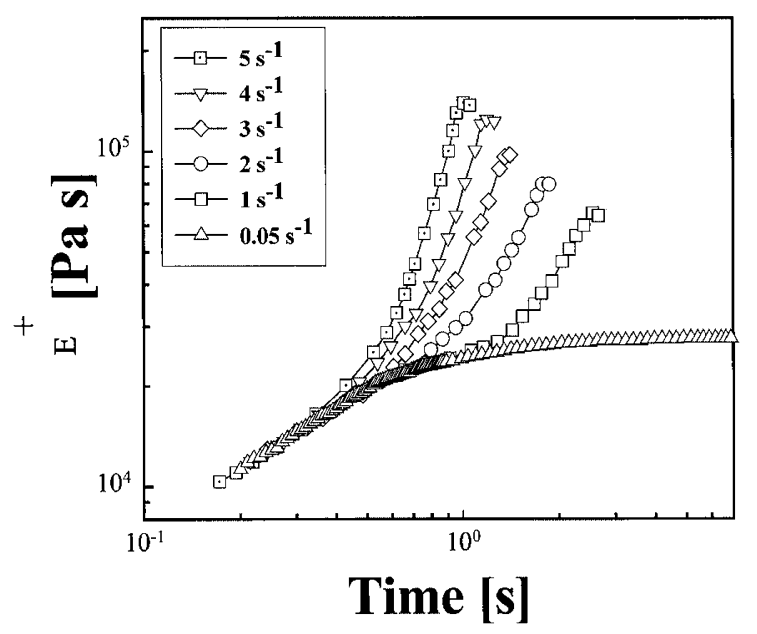

Figure 4. Transient extension viscosity growth curves at various extension rates $\left(\mathrm{s}^{-1}\right)$ with time for SAN: $(\triangle) 0.05,(\square) 1,(\bigcirc)$ $2,(\diamond) 3,(\nabla) 4,(\bullet) 5$.

was 0.38 and 0.28 , respectively. The weight fraction of phase inversion for PP in PP/SAN blend is shown in Table II for the Utracki, ${ }^{18}$ Miles and Zurek, ${ }^{19}$ and Metelkin and Blekht ${ }^{20}$ models.

\section{Morphology of the PP/SAN Blends}

The morphology of PP/SAN blends was studied by scanning electron microscopy. Figures $5 a, 5 b, 5 c$, and $5 \mathrm{~d}$ show micrographs of cryogenically fractured cross-section surfaces for 55/45, 50/50, 45/55, and 40/60 PP/SAN blends, respectively. In Figures 5a and $5 \mathrm{~b}$, PP and SAN show dispersed morphology, and the surfaces of PP and SAN phases look smooth and coarse, respectively. In Figures $5 \mathrm{~b}$ and $5 \mathrm{c}$, the $\mathrm{PP}$ and SAN show co-continuous morphology at compositions of $50 / 50$ and 45/55 PP/SAN blends. Frequently co-continuity was observed within a range 


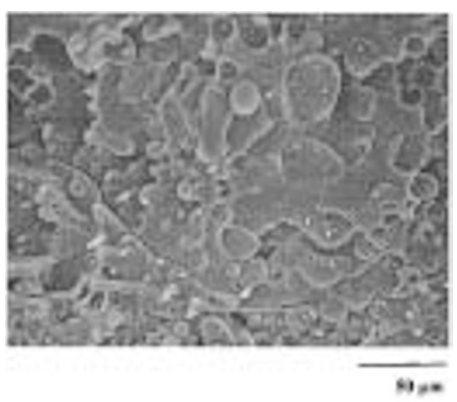

(a)

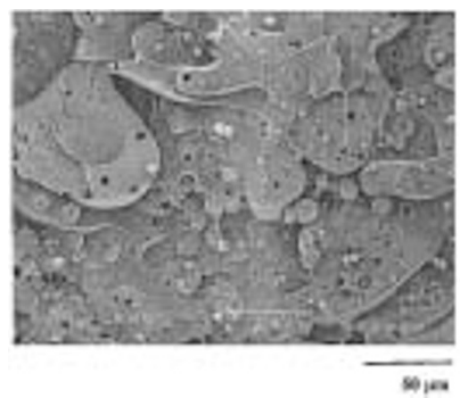

(b)

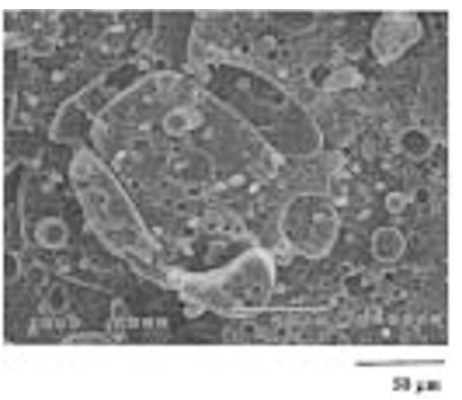

(c)

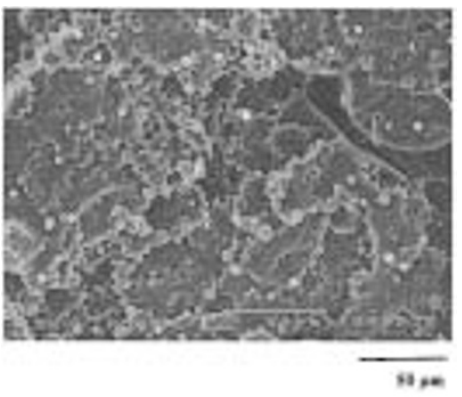

(d)

Figure 5. Scanning electron micrographs obtained from cryogenically fractured cross-section surfaces of PP/SAN blends: (a) 55/45; (b) $50 / 50$; (c) $45 / 55$; (d) 40/60.

of composition rather than at a single point, and similar morphological studies were reported for polyamide 6 (PA6)/polyethersulfone (PES) by He et al., ${ }^{13}$ hydroxypropylcellulose (HPC50\%)/poly(dimethylsiloxane) (PDMS) blends by Astruc and Navard, ${ }^{14}$ and for PDMS/poly(dimethylsiloxane-ran-methyphenylsiloxane) P(DMS-ran-MPS) by Ziegler and Wolf. ${ }^{16}$

From shear and extension viscosity data, Table II gives the weight fraction of phase inversion for PP in PP/SAN blends, as obtained by the Utracki, Miles and Zurek, and Metelkin and Blekht models. The Miles and Zurek model may be considered a special form of Metelkin and Blekht model, valid for $\lambda=1$. These models are suitable to predict the composition of phase inversion of blends when the viscosity ratio of the two components is unity. ${ }^{12}$ In contrast, the Utracki model predicts the point of phase inversion for blends with a viscosity ratio far away from unity. ${ }^{14}$ Utracki model may thus be suitable to predict the composition of phase inversion for PP/SAN blends.

In Table II, when the transient extension viscosity ratio was applied in the Utracki model, the composition of phase inversion in the PP/SAN blend shows good agreement with morphological studies.

From the results obtained by the extension rheometer in Figures 3 and 4, and morphological results in Figure 5, phase inversion seems related to transient extension viscosities of components at the inversion point during mixing.

\section{CONCLUSIONS}

In this study, extension and shear rheology of the polypropylene (PP) and poly(styrene-co-acrylonitrile) (SAN) were investigated by advanced rheometric expansion system (ARES), capillary rheometer, and extension rheometer.

Shear viscosity of PP and SAN was measured using a capillary rheometer, as $2.08 \times 10^{2}$ and $8.36 \times 10^{2} \mathrm{~Pa} \mathrm{~s}$ at a shear rate of $180 \mathrm{~s}^{-1}$, respectively. Transient extension viscosity of PP and SAN was obtained with an extensional rheometer as $1.63 \times 10^{4}$ and $2.62 \times 10^{4} \mathrm{Pas}$ at a shear rate of $4.10 \mathrm{~s}^{-1}$, the blending condition of the blends, respectively.

Shear and transient extension viscosity ratio were used in the Utracki, Miles and Zurek, and Metelkin and Blekht models to obtain the weight fraction of phase inversion for the blends. For the Utracki model, the weight fraction of phase inversion for PP in PP/SAN blend was 0.32 and 0.46 for the shear viscosity ratio and transient extension viscosity ratio of PP and SAN, respectively. From the scanning electronic microscopy, the phase inversion was in the region of $45 / 55 \mathrm{PP} / \mathrm{SAN}$ blends.

When the transient extension viscosity ratio was applied in the Utracki model, the composition of phase inversion in the PP/SAN blend showed good agreement with morphological studies. 
Acknowledgment. This study was supported by research grants from the Korea Science and Engineering Foundation (KOSEF) through the Applied Rheology Center (ARC), an official KOSEF-created engineering research center (ERC) at Korea University, Seoul, Korea.

\section{REFERENCES}

1. M. S. Han, D. W. Giles, and W. N. Kim, Polym. Eng. Sci., 45, 1506 (2001).

2. M. S. Han, J. H. Park, S. W. Cheen, S. H. Kim, and W. N. Kim, Polym. Bull., 45, 151 (2000).

3. M. S. Han, B. H. Lim, H. C. Jung, J. C. Hyun, and W. N. Kim, Korea-Australia Rheol. J., 13, 169 (2001).

4. W. N. Kim and M. M. Dean, J. Rheol., 36, 1477 (1992).

5. J. K. Lee and C. D. Han, Polymer, 40, 6277 (1999).

6. CHR. Friedrich, C. Weis, S. Steinmann, and D. Maier, Proceedings of the fifth European Rheology Conference, Portoroz, 1998, vol. 5, p 78.

7. C. Weis, CHR. Friedrich, K. Borkenstein, and D. Maier, Proceedings of the Polymer Processing Society 13th Annual Meeting, Secaucus, 1997, vol. 13, 6-A.

8. B. D. Favis and J. P. Chalifoux, Polymer, 39, 1761 (1998).

9. B. D. Favis and D. Therrien, Polymer, 32, 1474 (1992).

10. G. M. Jordhamo, J. A. Mason, and L. H. Sperling, Polym. Eng. Sci., 26, 517 (1986).

11. L. A. Utracki, "Polymer Alloys and Blends", Hanser, Munich, 1989.

12. N. Mekhilef and H. Verhoogt, Polymer, 37, 4069 (1996).

13. J. He, W. Bu, and J. Zeng, Polymer, 38, 6347 (1997).
14. M. Astruc and P. Navard, J. Rheol., 44, 693 (2000).

15. N. Mekhilef, B. D. Favis, and P. J. Carreau, J. Polym. Sci., Part B: Polym. Phys., 35, 293 (1997).

16. V. Ziegler and B. A. Wolf, J. Rheol., 43, 1033 (1999).

17. E. Földes, E. Fekete, F. E. Karasz, and B. Pukanszky, Polymer, 41, 975 (2000).

18. L. A. Utracki, J. Rheol., 35, 1615 (1991).

19. I. S. Miles and A. Zurek, Polym. Eng. Sci., 28, 796 (1988).

20. V. I. Metelkin and V. S. Blekht, Colloid J. USSR, 46, 425 (1984).

21. R. C. Willemse, De Boer A. Posthuma, J. Van Dam, and A. D. Gotsis, Polymer, 39, 5879 (1999).

22. R. C. Willemse, De Boer A. Posthuma, J. Van Dam, and A. D. Gotsis, Polymer, 40, 827 (1999).

23. R. C. Willemse, E. J. Ramaker, De Boer A. Posthuma, and J. Van Dam, Polymer, 40, 6651 (1999).

24. D. W. Van Krevelen, "Properties of Polymers," Elsevier Science Inc., New York, N.Y., 1990, p 71.

25. R. B. Bird, C. F. Curtiss, R. C. Armstrong, and O. Hassager, "Dynamics of Polymeric Liquids: Fluid Mechanics", John Wiley \& Sons, Inc., New York, N.Y., 1987, vol. 1, p 255.

26. H. W. Jung, J. S. Lee, W. N. Kim, and J. C. Hyun, Kor. J. Rheol., 8, 119 (1996).

27. H. W. Jung, K. Cho, and J. C. Hyun, Kor. J. Rheol., 9, 111 (1997).

28. I. M. Krieger and T. J. Dougherty, Trans. Soc. Rheol., 3, 137 (1959).

29. C. B. Martinez and M. C. Williams, J. Rheol., 24, 421 (1980).

30. A. D. Gotsis and A. Odriozola, Rheol. Acta, 37, 430 (1998).

31. A. D. Gotsis and Q. Ke, New York, N.Y., ANTEC, 1999, vol. $1, \mathrm{p} 1156$.

32. M. H. Wagner, Korea-Australia Rheol. J., 11, 293 (1999). 